\title{
Prevalences of parasitized and hyperparasitized crabs near South Georgia
}

\author{
George Watters* \\ U.S. AMLR Program, NOAA Fisheries, PO Box 271, San Diego, California 92038, USA
}

\begin{abstract}
This study identifies sources of variation in the prevalences of parasitized and hyperparasitized Paralomis spinosissima, a lithodid found around South Georgia. The parasite is Briarosaccus callosus, a rhizocephalan; the hyperparasite is an undescribed liriopsinine. Generalized additive models were used to model data collected during 1992 and 1995. Parasites were less prevalent on female crabs and most prevalent in submarine canyons. The former effect may be due to sex-specific differences in gill cleaning behavior, and the latter effect may result from reduced gill cleaning efficiency in areas where the seafloor is covered with fine sediment. The size-prevalence curve was dome-shaped; this probably indicates that $B$. callosus reduces the growth rate and increases the mortality rate of $P$. spinosissima. Parasite prevalence decreased with increasing crab density but increased with increasing parasitized crab density. These results suggest that parasitized crabs do not aggregate with unparasitized males. Habitat was a significant source of variation in hyperparasite prevalence during 1992 but not 1995. Between-year comparisons of parasite and hyperparasite prevalences were equivocal and failed to provide convincing evidence against parameter stationarity and stability in the $P$. spinosissima-B. callosus-liriopsinine system
\end{abstract}

KEY WORDS: Lithodid crabs - Rhizocephalan barnacles - Cryptoniscid isopods - Parasitism - Hyperparasitism - Prevalence - Generalized additive models

\section{INTRODUCTION}

Paralomis spinosissima is a lithodid crab that has recently been targeted by an exploratory fishery operating off the south Atlantic island of South Georgia. P. spinosissima is frequently parasitized by the rhizocephalan Briarosaccus callosus, and many of the rhizocephalans are, in turn, hosts for an hyperparasitic isopod (Otto \& MacIntosh 1996). The hyperparasite is currently undescribed, but it is believed to be from the family Cryptoniscidae (Otto \& MacIntosh 1996). Cryptoniscids comprise 7 subfamilies that can, in part, be separated on the basis of host specificity (Nielsen \& Strömberg 1973). The hyperparasite of B. callosus is probably from the subfamily Liriopsinae since these

\footnotetext{
- Present address: Inter-American Tropical Tuna Commission, 8604 La Jolla Shores Drive, La Jolla, California 92037, USA. E-mail: gwatters@iattc.ucsd.edu
}

isopods generally have rhizocephalan hosts (Caullery 1908, Nielsen \& Strömberg 1973).

Parasitized and hyperparasitized Paralomis spinosissima are easy to identify. A parasitized crab is recognizable when at least one externa (this is the rhizocephalan's reproductive structure) has emerged through the ventral abdominal cuticle. This method of identification may underestimate the true prevalence rate because there is a lag between the times of initial infection and emergence of the externa. A hyperparasitized crab is recognizable when at least one bulbous, sac-like structure (this is a female hyperparasite) has attached to the external surface of the rhizocephalan's externa.

Histological sections of parasitized crabs have shown that an individual Briarosaccus callosus can sterilize its crab host (Sparks \& Morado 1986), and histological sections of hyperparasitized rhizocephalans have shown that an individual liriopsinine can also sterilize its parasite host (Caullery 1908). These 
facts are important because they imply that the population-level consequences of parasitism and hyperparasitism in the paralomis spinosissima- $B$. callosus-liriopsinine system can be studied by considering prevalence rates rather than infection intensities (i.e. parasite and hyperparasite burdens). There are instances of multiple parasitism and hyperparasitism around South Georgia, but it is questionable whether these instances have a substantial impact on the system's dynamics. This view is supported by the work of Kuris (1974). Kuris noted that multiple infections by parasitic castrators and hypercastrators like rhizocephalans and Liriopsinae do not usually have additive pathogenic effects on individual hosts. The outcome from a single act of parasitic castration (or hypercastration) has the same population-level consequence (i.e. the 'reproductive death' of one host) as the outcome from an instance of multiple parasitic castration (or hypercastration).

In the case of Briarosaccus callosus, a second argument can be made for considering parasite prevalence rather than intensity of infection. The size of an externa is positively correlated with the host crab's carapace length, but the average size of externae involved in multiple infections is smaller than the average size of externae from single infections (Bower \& Sloan 1985). Under the reasonable assumption that the fecundity of $B$. callosus is positively correlated with externa size, the findings of Bower \& Sloan (1985) suggest that the total fecundity of a population of $B$. callosus is limited more by numbers and sizes of parasitized crabs than by numbers of parasite externae.

Briarosaccus callosus parasitizes at least 12 species of lithodid crabs (Boschma 1962, Hoggarth 1990, Pohle 1992a, Høeg 1995), and the prevalence of this rhizocephalan varies both between and within its host species. Between hosts, prevalence rates can vary from less than $1 \%$ (e.g. Paralomis granulosa from the Falkland Islands in Hoggarth 1990) to more than 75\% (e.g. Paralithodes platypus from Glacier Bay, Alaska in Hawkes et al. 1986b). A number of variables contribute to within-species variation in $B$. callosus prevalence. These variables include the sex and size of an individual host (e.g. Sloan 1984, Hawkes et al. 1985c, 1986b, Hoggarth 1990, Abelló \& Macpherson 1992) as well as the habitat from which an individual crab was captured (e.g. Sloan 1984, Hawkes et al. 1986a, b). Differences in local densities of unparasitized and parasitized crabs may also contribute to within-host variation in parasite prevalence. For example, Sloan (1984) observed prevalence rates between about 3 and $44 \%$ on Lithodes aequispina at locations where catches per unit of effort (catch rates are proxy estimates of local crab density) varied between about 3 and 24 crabs caught per trap fished.
Liriopsinae have been found on at least 3 lithodids that are known to be parasitized by Briarosaccus callosus: Paralomis bouvieri (Pohle 1992a), Neolithodes grimaldii (Pohle 1992b), and Paralomis spinosissima (Otto \& MacIntosh 1996). These 3 accounts contain few data on the prevalence of hyperparasitized crabs, and there is no information about which variables contribute to variation in hyperparasite prevalence. The literature does, however, contain information on variation in the prevalences of hosts parasitized by isopods from another subfamily in the Cryptoniscidae, the Cabiropsinae. Cabiropsinae parasitize isopods (Nielsen \& Strömberg 1973); some Cabiropsinae are parasites, others are hyperparasites. Nielsen \& Strömberg (1965) studied a parasitic cabiropsinine. They found that cabiropsinine prevalence varied with host sex, host maturity state, host size, and month. Nielsen \& Strömberg also noted that there may be geographical differences in cabiropsinine prevalence. Sassaman (1985) and Owens (1993) studied hyperparasitic Cabiropsinae. The hyperparasitic Cabiropsinae are typically hosted by bopyrid isopods (bopyrids parasitize many marine crustaceans, and the family Bopyridae is closely related to the Cryptoniscidae). Sassaman observed that cabiropsinine prevalence varied with changes in bopyrid abundance. Owens observed that cabiropsinine prevalence varied with season, geographical area, bopyrid size, the bopyrid host's size (in this case the bopyrids parasitized various species of prawns), and the bopyrid's host species.

The objective of this study is to develop an appropriate context for the construction of a mathematical hostparasite-hyperparasite model that describes the Paralomis spinosissima-Briarosaccus callosus-liriopsinine system (this mathematical model is presented in G. Watters \& R. Deriso unpubl.). This context development includes consideration of whether the $P$. spinosissima-B. callosus-liriopsinine system is governed by stationary (temporally invariant) population dynamics parameters and whether the system is stable. These 2 topics are addressed by a sequence of comparisons in which statistical models of parasite and hyperparasite prevalence rates are initially constructed from one set of data and then compared to data that were collected 3 yr later. Checks for stationarity and stability have not been made in previous studies of lithodid-B. callosus relationships.

\section{MATERIALS AND METHODS}

Data sources. Two data sets were used to study variation in the prevalence of parasitized and hyperparasitized Paralomis spinosissima; one data set was col- 
lected in 1992, and the other was collected in 1995. Otto \& MacIntosh (1996) made biological observations on a large sample of $P$. spinosissima; a subset of their observations comprised the '1992 data'. The 1992 data included records of the sex, size (carapace length in $\mathrm{mm}$ ), and parasitism and hyperparasitism states (present or absent) of individual crabs. The 1992 data also included records of the catch (number of legal-sized male crabs), effort (number of traps fished), and position of each haul from which these individuals were collected. The '1995 data' were collected by myself and a fishery observer. The 1995 data included the same types of information as the 1992 data. Both data sets were collected at different times of the year and cover different areas of the South Georgia coast. The 1992 data were collected in July; the 1995 data were collected in September. The 1992 data cover a small spatial area, and the 1995 data cover a large spatial area (Fig. 1A).

The haul positions from both data sets were used to determine whether there was habitatspecific variability in the prevalences of parasitized and hyperparasitized crabs. South Georgia's continental shelf is interrupted by a number of submarine canyons. The 1992 haul positions were overlaid on a fine-scale bathymetric map that delineates the offshore boundaries of one such canyon (Fig. 1B). Three types of habitat were identified from the map, and individual observations (crabs) in the 1992 data were categorized as being sampled from the submarine canyon, the canyon-slope transition, or the continental slope (Fig. 1B). A larger scale nautical chart (British Admiralty 1991) was used to determine whether individual observations in the 1995 data were sampled from the slope, transition, or canyon habitats.

Tables 1 \& 2 list the predictor variables that were used to account for variability in the prevalences of parasitized and hyperparasitized Paralomis spinosissima and summarize the contents of the 1992 and 1995 data sets. The number of legal-sized (carapace length greater than $102 \mathrm{~mm}$ ) male crabs caught per trap set (catch per unit effort or CPUE) was used as a proxy estimate of the overall crab density at each haul position. A proxy estimate of parasitized crab density at each haul position was obtained by multiplying the haul-specific CPUE and the haul-specific parasite prevalence rate. Note that while many of the hauls were spatially close together (see Fig. 1B for an example of inter-haul spacing), data from neighboring hauls
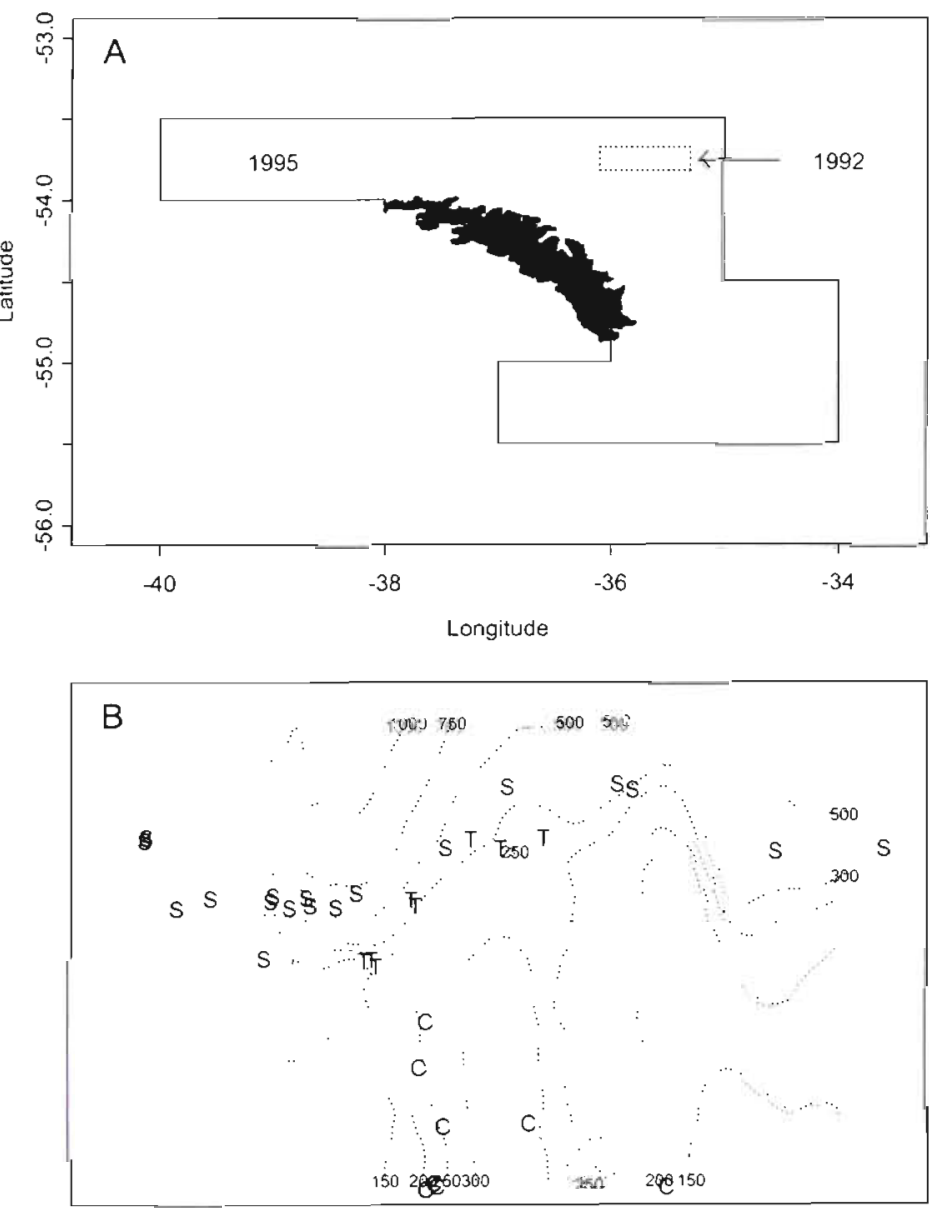

Fig. 1 (A) Spatial coverage of the 1992 and 1995 data. The position of the 1992 data is not plotted in its actual location because this information is confidential. (B) Detailed bathymetry of the location where the 1992 data were collected. Latitudes and longitudes are not provided because the haul positions are confidential. C: hauls made in the submarine canyon; $\mathrm{T}$. hauls made in the transitional area between the canyon and the continental slope; and S: hauls made on the continental slope. Depth contours are in meters, and collection of the bathymetric data is described in Watters et al. (1995)

were assumed to be independent. This assumption seemed justified given Watters' (1997) observation that CPUEs from spatially and temporally adjacent hauls are highly variable.

The 1992 and 1995 data were collected in a manner that introduced 2 types of variability into parasite and hyperparasite prevalence rates: between-haul variation and within-haul variation. Between-haul variation was introduced by sampling crabs from a random selection of hauls; within-haul variation was introduced by sampling crabs from a random selection of the traps lifted during a single haul the traps were fished on a longline). The models described below captured between-haul variation in parasite and hyperparasite prevalence rates; within-haul variation was 
Table 1. Summary statistics of the data used to construct the parasitism models ( $n$ is the sample size). Proxies for crab density and parasitized crab density were calculated from haulby-haul catch rates

\begin{tabular}{|c|c|c|c|}
\hline $\begin{array}{l}\text { Variable } \\
\text { Statistic }\end{array}$ & 1992 & 1995 & $1992+1995$ \\
\hline \multicolumn{4}{|l|}{ Parasites } \\
\hline n absent & 3107 & 1520 & 4627 \\
\hline$n$ present & 596 & 142 & 738 \\
\hline \multicolumn{4}{|l|}{ Habitat } \\
\hline$n$ slope & 1985 & 1029 & 3014 \\
\hline$n$ transition & 1055 & 234 & 1289 \\
\hline n canyon & 663 & 399 & 1062 \\
\hline \multicolumn{4}{|l|}{ Sex } \\
\hline$n$ female & 2005 & 753 & 2758 \\
\hline$n$ male & 1698 & 909 & 2607 \\
\hline \multicolumn{4}{|c|}{ Carapace length (mm) } \\
\hline$n$ & 3703 & 1662 & 5365 \\
\hline Minimum & 32 & 46 & 32 \\
\hline Median & 90 & 90 & 90 \\
\hline Maximum & 127 & 122 & 127 \\
\hline \multicolumn{4}{|l|}{ Crab density } \\
\hline$n$ sets & 34 & 36 & 70 \\
\hline Minimum & 0.33 & 0.38 & 0.33 \\
\hline Median & 6.82 & 8.53 & 6.82 \\
\hline Maximum & 16.49 & 15.98 & 16.49 \\
\hline \multicolumn{4}{|c|}{ Parasitized crab density } \\
\hline$n$ sets & 34 & 36 & 70 \\
\hline Minimum & 0.00 & 0.00 & 0.00 \\
\hline Median & 0.87 & 0.37 & 0.79 \\
\hline Maximum & 2.92 & 2.14 & 2.92 \\
\hline
\end{tabular}

considered to represent a scale of variability that was outside the scope of this study.

Modeling strategy. Generalized additive models (GAMs) were used to identify sources of variation in the prevalences of parasitized and hyperparasitized Paralomis spinosissima. The GAMs were developed in a logistic regression framework. The random component of variation in the number of parasitized (or hyperparasitized) crabs from a sample of $n$ individuals is assumed to follow a binomial distribution where the probability of success is an estimate of the true parasite (or hyperparasite) prevalence rate. The logistic regression model is well suited to the analysis of both data sets because the sample sizes of unparasitized, parasitized, and hyperparasitized crabs were not fixed prior to data collection. These sample sizes are random variables reflecting the true prevalence rates (see McCullagh \& Nelder 1989 for arguments regarding the applicability of the logistic regression approach to retrospectively sampled data). The GAMs were constructed following various techniques outlined in Hosmer \& Lemenshow (1989), McCullagh \& Nelder (1989), Hastie \& Tibshirani (1990), Collett (1991), and Chambers \& Hastie (1993). All of the modeling was con-
Table 2. Summary statistics of the data used to construct the hyperparasitism models ( $\mathrm{n}$ is the sample size). Proxies for parasitized crab density were calculated from haul-by-haul catch rates

\begin{tabular}{|c|c|c|c|}
\hline $\begin{array}{l}\text { Variable } \\
\text { Statistic }\end{array}$ & 1992 & 1995 & $1992+1995$ \\
\hline \multicolumn{4}{|l|}{ Hyperparasites } \\
\hline$n$ absent & 465 & 115 & 580 \\
\hline$n$ present & 131 & 27 & 158 \\
\hline \multicolumn{4}{|l|}{ Habitat } \\
\hline n slope & 240 & 113 & 353 \\
\hline$n$ transition & 139 & 15 & 154 \\
\hline$n$ canyon & 217 & 14 & 231 \\
\hline \multicolumn{4}{|c|}{ Parasitized crab density } \\
\hline$n$ sets & 33 & 25 & 58 \\
\hline Minimum & 0.07 & 0.05 & 0.05 \\
\hline Median & 1.38 & 1.23 & 1.37 \\
\hline Maximum & 2.92 & 2.14 & 2.92 \\
\hline
\end{tabular}

ducted with functions that are implemented in S-Plus (Statistical Sciences 1995).

Predictors of parasite prevalence were contained in a matrix named $\mathbf{x}_{\mathrm{P}}$ (the subscript ' $\mathrm{P}$ ' denotes parasitism). $\mathbf{x}_{\mathrm{P}}$ contained column vectors for variables representing habitat (transition and canyon), sex (sex), carapace length in $\mathrm{mm}(s)$, crab density ( $c d$ ), parasitized $\mathrm{crab}$ density ( $p d)$, and the 'most significant' predictor interaction (i) (see following paragraphs for additional descriptions of this interaction term). Transition and canyon were indicator variables in a treatment contrast scheme. Transition $=$ canyon $=0$ for crabs collected from the continental slope; transition $=1$, and canyon $=$ 0 for crabs collected from the transition habitat; and transition $=0$, and canyon $=1$ for crabs collected from a submarine canyon. Males were contrasted against females (sex $=1$ for males, and sex $=0$ for females).

Predictors of hyperparasite prevalence were contained in a matrix named $\mathbf{x}_{\mathrm{H}}$ (the subscript ' $\mathrm{H}$ ' denotes hyperparasitism). $\mathbf{x}_{H}$ contained column vectors for variables representing habitat (transition and canyon), parasitized crab density $(p d)$, and the interaction between habitat and parasitized crab density. The habitat contrast scheme was the same as that used in $\mathrm{x}_{\mathrm{P}}$.

The logarithm of the odds (log-odds) that a crab was parasitized in 1992 was modeled by

$$
\begin{aligned}
& \ln \left[\frac{\pi_{1992}\left(\mathbf{x}_{\mathrm{P}}\right)}{1-\pi_{1992}\left(\mathbf{x}_{\mathrm{P}}\right)}\right]=g_{1992}\left(\mathbf{x}_{\mathrm{P}}\right) \\
& =\beta_{\mathrm{P}, 0}+\beta_{\mathrm{P}, 1} \text { transition }+\beta_{\mathrm{P}, 2} \text { canyon }+\beta_{\mathrm{P}, 3} \text { sex } \\
& \quad+f_{\mathrm{P}, 4}(s)+f_{\mathrm{P}, 5}(\mathrm{~cd})+f_{\mathrm{P}, 6}(p d)+\beta_{\mathrm{P}, 7} i
\end{aligned}
$$

where $\pi_{1992}\left(\mathbf{x}_{\mathrm{P}}\right)=\operatorname{Pr}\left(\right.$ crab was parasitized in $\left.1992 \mid \mathbf{x}_{\mathrm{P}}\right)$, and the $\beta$ s are parameters. $g_{1992}\left(\mathbf{x}_{P}\right)$ is called the '1992 parasitism model'. The main effects in this model were screened by forward selection and backward elimina- 
tion using the Akaike Information Criterion (AIC) (see Chambers \& Hastie 1993 for details on this stepwise variable selection approach).

The log-odds that a crab was hyperparasitized in 1992 was modeled by

$$
\begin{aligned}
\ln \left[\frac{\pi_{1992}\left(\mathbf{x}_{\mathrm{H}}\right)}{1-\pi_{1992}\left(\mathbf{x}_{\mathrm{H}}\right)}\right]=g_{1992}\left(\mathbf{x}_{\mathrm{H}}\right) \\
=\beta_{\mathrm{H}, 0}+\beta_{\mathrm{H}, 1} \text { transition }+\beta_{\mathrm{H}, 2 \text { canyon }+f_{\mathrm{H}, 3}(p d)} \\
\quad+\beta_{\mathrm{H}, 4}[\text { transition } p d]+\beta_{\mathrm{H}, 5}[\text { canyon } p d]
\end{aligned}
$$

where $\pi_{1992}\left(\mathbf{x}_{\mathrm{H}}\right)=\operatorname{Pr}(\mathrm{crab}$ was hyperparasitized in 1992 । $\left.\mathbf{x}_{\mathrm{H}}\right) \cdot g_{1992}\left(\mathbf{x}_{\mathrm{H}}\right)$ is called the '1992 hyperparasitism model', and the main effects in this model were also screened by forward selection and backward elimination.

The smooth terms (the fs) in Eqs. (1) \& (2) were modeled with smoothing splines. The smoothness of each spline was adjusted by specifying its approximate degrees of freedom (df). Adjusting the degrees of freedom for the various smooth terms in a GAM is approximately equivalent to adjusting the number of parameters in the model (Hastie \& Tibshirani 1990). The degrees of freedom for the smooth terms in Eqs. (1) \& (2) were adjusted by starting with $\mathrm{df}=4$ and comparing the fits of models with $\mathrm{df}=\{3,2,1\}$ to the fit of the 'full' df $=4$ model. This comparison was made by an approximate deviance $(D)$ test based on the $\chi^{2}$ distribution (Hastie \& Tibshirani 1990):

$$
D_{\mathrm{df}=i \sim 1}-D_{\mathrm{df}=1} \sim \chi_{1}^{2}
$$

The df of each smooth term was reduced until the deviance of the 'reduced' model was significantly different from the deviance of the 'full' model $(\alpha=0.05)$. Note that with $1 \mathrm{df}$ a smoothing spline is a linear term.

Since variable selection via the AIC often results in generous addition of predictors (Venables \& Ripley 1994), the deviance test in Expression (3) was also used to check for the 'overall' significance of each term in the two 1992 models ( $\alpha=0.05$ ). The 'final' 1992 models were obtained by dropping insignificant terms from Eqs. (1) \& (2)

The 'most significant' interaction in the 1992 parasitism model ( $i$ in Eq. 1) was identified in a 2-step process. First, the number of potential interactions was limited by only considering first-order interactions that involved one or more of the significant categorical predictors (interactions between 2 continuous predictors were not considered): [sex.s], [sex $c d]$, [sex $\cdot p d]$, [sex $\cdot$ transition] with [sex $\cdot$ canyon], [transition $\cdot s]$ with [canyon $\cdot s]$, [transition $\cdot c d]$ with [canyon $\cdot c d]$, or [transition $\cdot p d]$ with [canyon $\cdot p d]$. Second, these interactions (or the single interaction pairs involving transition and canyon) were individually substituted for $i$ in $g_{1992}\left(\mathbf{x}_{\mathrm{P}}\right)$, and approximate deviance tests ( $\chi^{2}$ distribution) were conducted to determine whether each individual interaction explained a significant amount of variation in the log-odds of being parasitized. The individual interaction with the lowest $p$-value from these deviance tests was labeled 'most significant' and permanently included in $g_{1992}\left(\mathbf{x}_{\mathrm{P}}\right)$. The interaction selection process was not necessary for $g_{1992}\left(\mathbf{x}_{\mathrm{H}}\right)$ because this model only included one categorical predictor (see Eq. 2).

Between-year comparisons. Three between-year comparisons were made. First, the two 1992 models were used to explain variation in the 1995 data. This comparison was conducted by using the 1992 models to make predictions from the 1995 observations, conputing the residual deviance $\left(D_{1995}\right.$ new $)$, and using an approximate deviance test ( $\chi^{2}$ distribution; $\alpha=0.05$ ) to determine whether the 1992 models explained significant amounts of variation in the 1995 data. The residual deviance from using a 1992 model to explain variation in the 1995 data is given by

$$
D_{1995, \text { new }}=\sum_{j=1}^{n} r_{\text {dev }, j}^{2}
$$

where

$$
I_{\text {dev }, j}=\operatorname{sgn}\left(y_{j}-\hat{\pi}_{j}\right) \sqrt{-2\left[y_{j} \ln \left(\hat{\pi}_{j}\right)+\left(1-y_{j}\right) \ln \left(1-\hat{\pi}_{j}\right)\right.}
$$

The observed value of parasitism or hyperparasitism is $y_{j}\left(y_{j}=0\right.$ or 1$)$, and $\tilde{\pi}_{j}$ is the probability of being parasitized (or hyperparasitized) predicted by the 1992 model. The function 'sgn' indicates the sign of the difference between the observed at the predicted. The approximate deviance test is given by

$$
D_{1995, \text { new }}-D_{1995, \text { null }} \sim \chi_{1995, \text { new,df }-1}^{2}
$$

where the null deviance $\left(D_{1995, \text { null }}\right)$ is the residual deviance from using the 1995 mean log-odds to explain variation in the 1995 data. Expression (6) is a generalized likelihood ratio test and requires that the null and new models are 'structurally' nested (i.e. that the form of the new model contains the null model). Such nesting does not imply that the parameters of the 2 models must be estimated from the same data. The likelihood ratio test can be used to compare the fits of 2 structurally nested models no matter how each set of parameters is estimated.

In the second comparison, Eqs. (1) \& (2) were refitted to the 1995 data using all of the significant terms from the final 1992 models. This comparison was done to determine whether, via $\chi^{2}$ deviance tests, significant predictors for the 1992 data were also significant for the 1995 data.

The final between-year comparison was made by combining the 1992 data and 1995 data and testing for a significant year effect and significant [year - sex] and [year habitat] interactions ( $\chi^{2}$ deviance tests; $\alpha=0.05$ ). The combined models were parameterized so that 1995 was contrasted against 1992 (i.e. year $=0$ for 1992 , and year $=1$ for 1995). The combined models 
were also used to test whether odds ratios from the combined model were significantly different than unity $\left(H_{0}: \Psi_{1992+1995}=1.0\right)$ (see Hosmer \& Lemenshow 1989 and Collett 1991 for examples of this process). Standard errors of the parameters from the combined models were approximated by replacing the smoothing splines with natural splines, refitting the models by weighted least squares, and obtaining the inverses of the estimated Fisher information matrices (Chambers \& Hastie 1993 suggested this approach). These standard errors are conservative (i.e. the approximations are positively biased).

\section{RESULTS}

\section{2 models}

All of the main effects in the 1992 parasitism model explained a significant amount of the variation in the log-odds of being parasitized, and the [habitat.sex] interaction was the most significant interaction

Table 3. Analysis of deviance tables from the parasitism models. Results are shown for the 'overa.l' effect of each variable. $p$-values are reported from testing the significance of sequentially adding each effect (in the order listed) to the model. $c d$ : crab density; $p d$ : parasitized crab density

\begin{tabular}{|c|c|c|c|c|c|}
\hline $\begin{array}{l}\text { Included } \\
\text { effects }\end{array}$ & $\mathrm{df}$ & Deviance & $\begin{array}{l}\text { Residual } \\
\quad \mathrm{df}\end{array}$ & $\begin{array}{l}\text { Residual } \\
\text { deviance }\end{array}$ & $\mathrm{p}$ \\
\hline \multicolumn{6}{|c|}{$\begin{array}{l}\text { Eq (1) fitted to } 1992 \text { parasitism data: } \\
\text { null deviance }=3267.84\end{array}$} \\
\hline+ habitat effect & 2 & 143.34 & 3700 & 3124.50 & $<0.0001$ \\
\hline+ size effect & 4 & 1063.48 & 3 & 2061.02 & $<0.0001$ \\
\hline+ sex effect & 1 & 69.16 & 3695 & 1991.86 & $<0.0001$ \\
\hline$+c d$ effect & 3 & 31 & 3692 & 1960.33 & $<0.0001$ \\
\hline$+p d$ effect & 4 & 153 & 36 & & $<0.0001$ \\
\hline $\begin{array}{l}+\mid \text { habitat } \cdot s e x] \\
\text { interaction }\end{array}$ & 2 & 5 & 36 & 05 & $<0.0001$ \\
\hline \multicolumn{6}{|c|}{$\begin{array}{l}\text { Eq. (1) fitted to } 1995 \text { parasitism data: } \\
\text { null deviance }=970.13\end{array}$} \\
\hline + habitat effect & 2 & 25.06 & 1659 & 945.07 & $<0.0001$ \\
\hline + size effect & 4 & 213.48 & 16 & 731.60 & $<0.0001$ \\
\hline+ sex effect & 1 & 11.34 & 16 & 720 & 0.0008 \\
\hline$+c d$ effect & 3 & 30.22 & 16 & 690.04 & $<0.0001$ \\
\hline$+p d$ effect & 4 & 71.69 & 1647 & 618.35 & $<0.0001$ \\
\hline $\begin{array}{l}+[\text { habitat } \cdot \operatorname{sex}] \\
\text { interaction }\end{array}$ & 2 & 2.79 & 1645 & 615.56 & 0.2484 \\
\hline \multicolumn{6}{|c|}{$\begin{array}{l}\text { Combined model fitted to } 1992+1995 \text { parasitism data: } \\
\text { null deviance }=4297.43\end{array}$} \\
\hline + habitat effect & 2 & 64.78 & 5362 & 4232.65 & $<0.0001$ \\
\hline+ size effect & 4 & 1320.64 & 5358 & 2912.01 & $<0.0001$ \\
\hline+ sex effect & 1 & 83.51 & 5357 & 2828.50 & $<0.0001$ \\
\hline - cd effect & 3 & 67.89 & 5354 & 2760.61 & $<0.0001$ \\
\hline$+p d$ effect & 4 & 271.49 & 5350 & 2489.12 & $<0.0001$ \\
\hline + year effect & 1 & 24.68 & 5349 & 2464.44 & $<0.0001$ \\
\hline
\end{tabular}

(Table 3). The final parasitism model for 1992 was

$$
\begin{aligned}
& \hat{g}_{1}\left(\mathbf{x}_{\mathrm{P}}\right)=12.50+0.06 \text { transition }+2.58 \text { canyon } \\
& +1.32 \text { sex }+\hat{f}_{\mathrm{P}, 4}(s)+\hat{f}_{\mathrm{P}, 5}(\mathrm{~cd})+\hat{f}_{\mathrm{P}, 6}(p d) \\
& \quad-0.04[\text { transition } \cdot \text { sex }]-2.00[\text { canyon sex }]
\end{aligned}
$$

The smoothing spline for size $\left[\hat{f}_{\mathrm{P}, 4}(s)\right]$ had approximately $4 \mathrm{df}_{i}$ the spline for crab density $\left\{\hat{f}_{\mathrm{P}, 5}(c d)\right\}$ had approximately $3 \mathrm{df}$; and the spline for parasitized crab density $\left[\hat{f}_{\mathrm{P}, 6}(p d)\right]$ had approximately $4 \mathrm{df}$. The 3 smoothing splines predicted that parasite prevalence was dome-shaped with respect to crab size, decreased to an asymptotically low level with increasing crab density, and increased according to a flattened ' $s$ 'curve with increasing parasitized crab density. These 3 trends can be seen in Figs. 2 to 4 , but the results in these figures were actually predicted by the parasitism model which was fitted to the combined $1992+1995$ data sets (see 'Between-year comparisons' below). Parameters for the categorical predictors and the pair of interaction terms predicted that Briarosaccus callosus was more prevalent on males than females in the slope and transition habitats, but less prevalent on males in the canyon habitat. This interaction is not illustrated in Figs. 2 to 4 because the interaction was not consistent between years (see 'Between-year comparisons' below).

In the 1992 hyperparasitism model, habitat explained a significant amount of variation in the logodds of being hyperparasitized, but parasitized crab density was not a significant predictor variable (Table 4). Since habitat was the only significant term, there were no interaction terms in this model. The final hyperparasitism model for 1992 was

$$
\hat{g}_{1992}\left(\mathbf{x}_{\mathrm{H}}\right)=-1.24+0.37 \text { transition }-0.38 \text { canyon }
$$

The habitat parameters predicted that hyperparasitized crabs were most prevalent in the transition habitat and least prevalent in the canyon habitat.

Table 4. Analysis of deviance tables from the hyperparasitism models. Results are shown for the 'overall' effect of each vari-

\begin{tabular}{|c|c|c|c|c|c|}
\hline $\begin{array}{l}\text { Included } \\
\text { effects }\end{array}$ & $\mathrm{df}$ & Deviance & $\begin{array}{l}\text { Residual } \\
\quad \text { df }\end{array}$ & $\begin{array}{l}\text { Residual } \\
\text { deviance }\end{array}$ & $p$ \\
\hline \multicolumn{6}{|c|}{$\begin{array}{l}\text { Eq. (2) fitted to } 1992 \text { hyperparasitism data: } \\
\text { null deviance }=627.77\end{array}$} \\
\hline + habitat effect & 2 & 8.23 & 593 & 619.54 & 0.0163 \\
\hline + pd effect & 1 & 0.30 & 592 & 619.24 & 0.5841 \\
\hline \multicolumn{6}{|c|}{$\begin{array}{l}\text { Eq. (2) fitted to } 1995 \text { hyperparasitism data: } \\
\text { null deviance }=138.15\end{array}$} \\
\hline + habitat effect & 2 & 2.14 & 139 & 136.01 & 0.3430 \\
\hline$+p d$ effect & 1 & 1.02 & 138 & 134.99 & 0.3133 \\
\hline
\end{tabular}
able. p-values are reported from testing the significance of sequentially adding each effect (in the order listed) to the model. pd: parasitized crab density 


\section{Between-year comparisons}

In the first between-year comparison, the final 1992 parasitism model explained a significant amount of variation in the log-odds of being parasitized during 1995 (Table 5). The 1992 model explained less variation than was explained by refitting Eq. (1) to the 1995 data, but the significance level of the 1992 model was comparable to that of the refitted 1995 model (Table 5).

In contrast to the parasitism model, the final 1992 hyperparasitism model did not explain a significant amount of variation in the 1995 data (Table 6). Note, however, that refitting Eq. (2) to the 1995 data also failed to explain a significant amount of variation in the log-odds of being hyperparasitized (i.e. habitat was not significant in the refitted model) (Table 4).

The second comparison showed that all of the main effects in Eq. (7) were consistent, between-year sources of variation in the log-odds of being parasitized. All of the main effects from the final 1992 parasitism model were also significant in the refitted 1995 parasitism model, but the [habitat-sex] interaction was not significant in the 1995 parasitism model (Table 3). Crab size and parasitized crab density explained the most variation in the log-odds of being parasitized during 1992; this was also evident from the 1995 model (Table 3).

With respect to hyperparasitism, the second comparison showed that habitat was not a consistent, between-year source of variation in the log-odds of being hyperparasitized. This was evident because habitat was not significant in the 1995 hyperparasitism model (Table 4).

Despite the between-year similarities of the 1992 and 1995 parasitism models

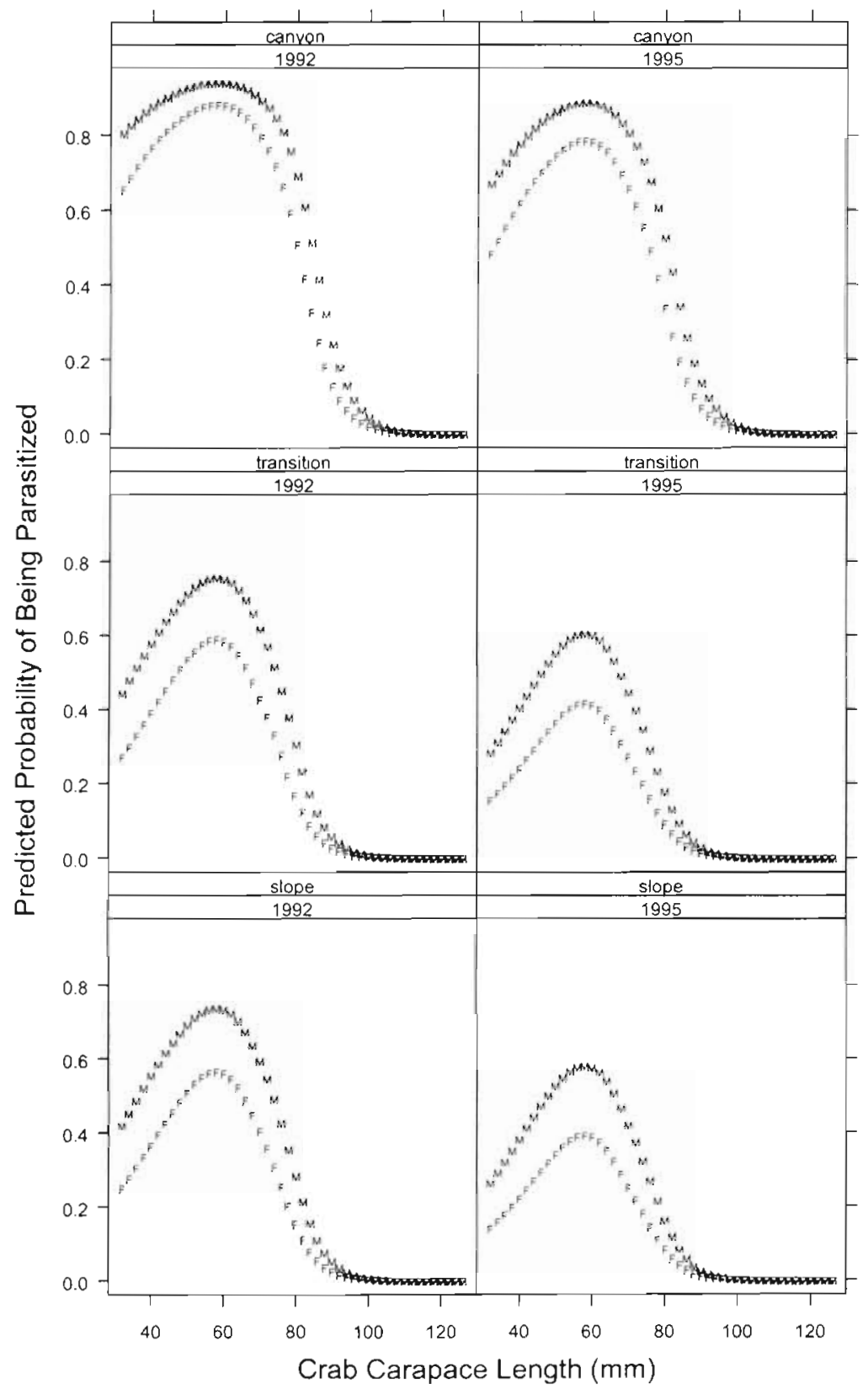

Fig. 2. Size-prevalence curves for crabs predicted by the combined parasitism model. The predictions were made at the median levels of $c d$ (crab density) and $p d$ (parasitized crab density). M: male crabs; F: females. Each panel is a unique combination of year and habitat
Table 5. Analysis of deviance table comparing various models that were used to explain variation in the 1995 parasitism data

\begin{tabular}{|lcrrrrrcc|}
\hline $\begin{array}{l}\text { Model for } \\
\text { 1995 data }\end{array}$ & ID & df & Deviance & $\begin{array}{c}\text { Residual } \\
\text { df }\end{array}$ & $\begin{array}{c}\text { Residual } \\
\text { deviance }\end{array}$ & Test & $p$ \\
\hline Intercept (null) & 1 & 1 & & 1661 & 970.13 & & \\
1.992 model & 2 & 17 & 190.50 & 1645 & 779.63 & 2 vs 1 & $<0.001$ \\
1995 model & 3 & 17 & 354.57 & 1645 & 615.56 & 3 vs 1 & $<0.001$ \\
\hline
\end{tabular}

that were demonstrated by the first 2 comparisons, a significant year effect was estimated by combining the 2 parasitism data sets (Table 3 ). The combined parasitism model predicted that Briarosaccus callosus was less prevalent in 1995 than in 1992 (Figs. 2 to 4). However, when year was the last term added to the combined model, the 


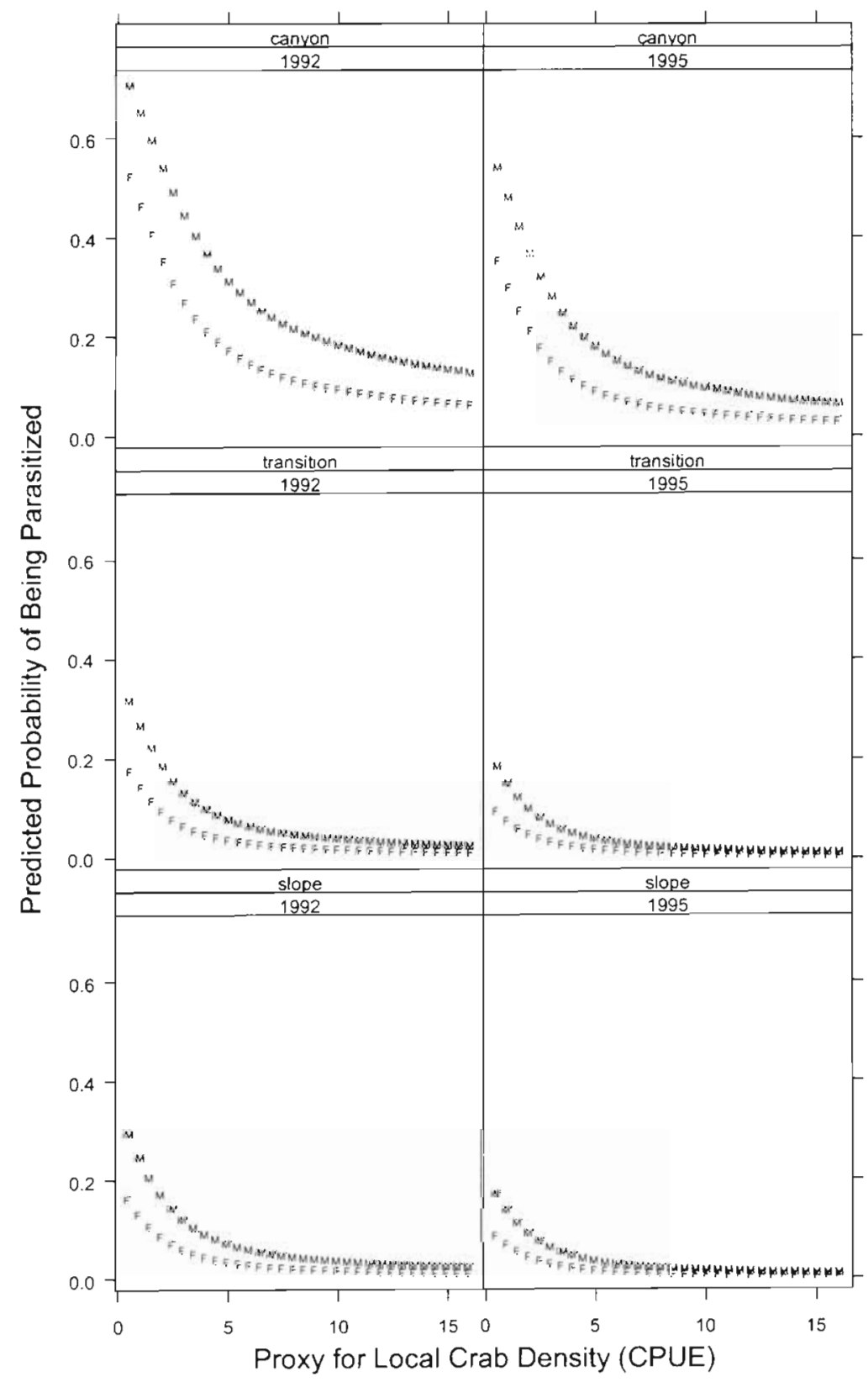

Fig. 3. Relationship between parasite prevalence and crab density (CPUE: catch per unit effort) predicted by the combined parasitism model. The predictions were made at the median levels of $s$ (carapace length) and $p d$ (parasitized crab density). M: male crabs; F: females. Each panel is a unique combination of year and habitat

year effect explained less variation in the log-odds of being parasitized than any other main effect (Table 3 ). Neither the [year-sex] interaction nor the [year-habitat] interaction was significant in the combined parasitism model ( $p=0.31$ and $p>0.50$, respectively).

The combined parasitism model made predictions that were similar to those made by the 1992 parasitism model. The combined parasitism model was

$$
\begin{gathered}
\hat{g}_{1992+1995}\left(\mathbf{x}_{\mathrm{P}}\right)=10.31+0.10 \text { transition } \\
+1.74 \text { canyon }+0.78 \text { sex }+\hat{f}_{\mathrm{P}, 4}(s) \\
+\hat{f}_{\mathrm{P} .5}(c d)+\hat{f}_{\mathrm{P}, 6}(p d)-0.71 \text { year }
\end{gathered}
$$

For the continuous predictors, the combined model predicted that the sizeprevalence curve was dome-shaped (Fig. 2), that prevalence decreased towards an asymptote as local crab density increased (Fig. 3), and that prevalence increased according to a flat ' $s$ '-curve when the local density of parasitized crabs increased (Fig. 4). For the categorical predictors, the combined model predicted that female crabs were about half as likely to be parasitized as males, that crabs of both sexes were about 6 times more likely to be parasitized in a submarine canyon than they were on the continental slope, and that crabs were about half as likely to be parasitized in 1995 as they were in 1992 (Table 7).

The null hypothesis that hyperparasite prevalence was independent of year was tested with a $\chi^{2}$ test for heterogeneity (adjusted by Yate's continuity correction). The prevalence of hyperparasitized crabs was $22 \%$ (of parasitized crabs) in 1992 and $19 \%$ in 1995 (Table 2), and this test failed to reject the null hypothesis $(p>0.50)$.

\section{DISCUSSION}

\section{Trends in the prevalence of Briarosaccus callosus}

Since the combined parasitism model was constructed from data that covered a large spatial area (Fig. 1A) and 2 different periods in time, trends in the prevalence of Briarosaccus callosus will be discussed from the results of this model (Eq. 9). The combined parasitism model provided results that were often consistent with findings from studies of other lithodid- $B$. callosus systems

As measured by prevalence rates, Briarosaccus callosus does not exhibit a clear preference for male or female hosts. B. callosus can be more prevalent on male crabs (e.g. Paralomis spinosissima in this study and Otto \& MacIntosh 1996, Lithodes aequispina in Hawkes et al. 1986b), more prevalent on female crabs 
(e.g. Paralithodes platypus in Hawkes et al. 1985b, c, 1986b), or equally prevalent on males and females (e.g. L. aequispina in Sloan 1984, Paralithodes camtschaticus in Hawkes et al. 1986b, Paralomis granulosa in Hoggarth 1990, Lithodes ferox in Abelló \& Macpherson 1992). Hawkes et al. (1986b) suggested that selective harvesting of unparasitized males might explain situations where prevalence is higher on females, but they did not offer an explanation for why, in other situations, B. callosus is less prevalent on females.

Lower prevalence rates on female crabs might be explained by sex-specific differences in grooming efficiency or by parasite-induced pleopod loss in females. Neither of these suggestions has been specifically addressed for a Briarosaccus callosus system, and each topic is discussed below.

An unparasitized crab can become parasitized when a Briarosaccus callosus larva (a cyprid) successfully attaches to its gill (Hawkes et al. 1985c), and grooming efficiency is widely recognized as an important determinant of whether individual crabs are parasitized by rhizocephalans (Ritchie \& Høeg 1981, Pohle 1989, Fleischer et al. 1992). If females from some lithodids have grooming limbs or grooming behaviors that provide more efficient gill cleaning than the limbs or behaviors of males, it is reasonable to expect that $B$. callosus would be less prevalent on females. Female lithodids clean both their gills and their egg masses with the fifth pair of pereiopods (Pohle 1989); perhaps females, in adapting to the potential selective pressures of brood care, have also become more efficient at gill cleaning.

If there are sex-specific differences in grooming efficiency, it seems more

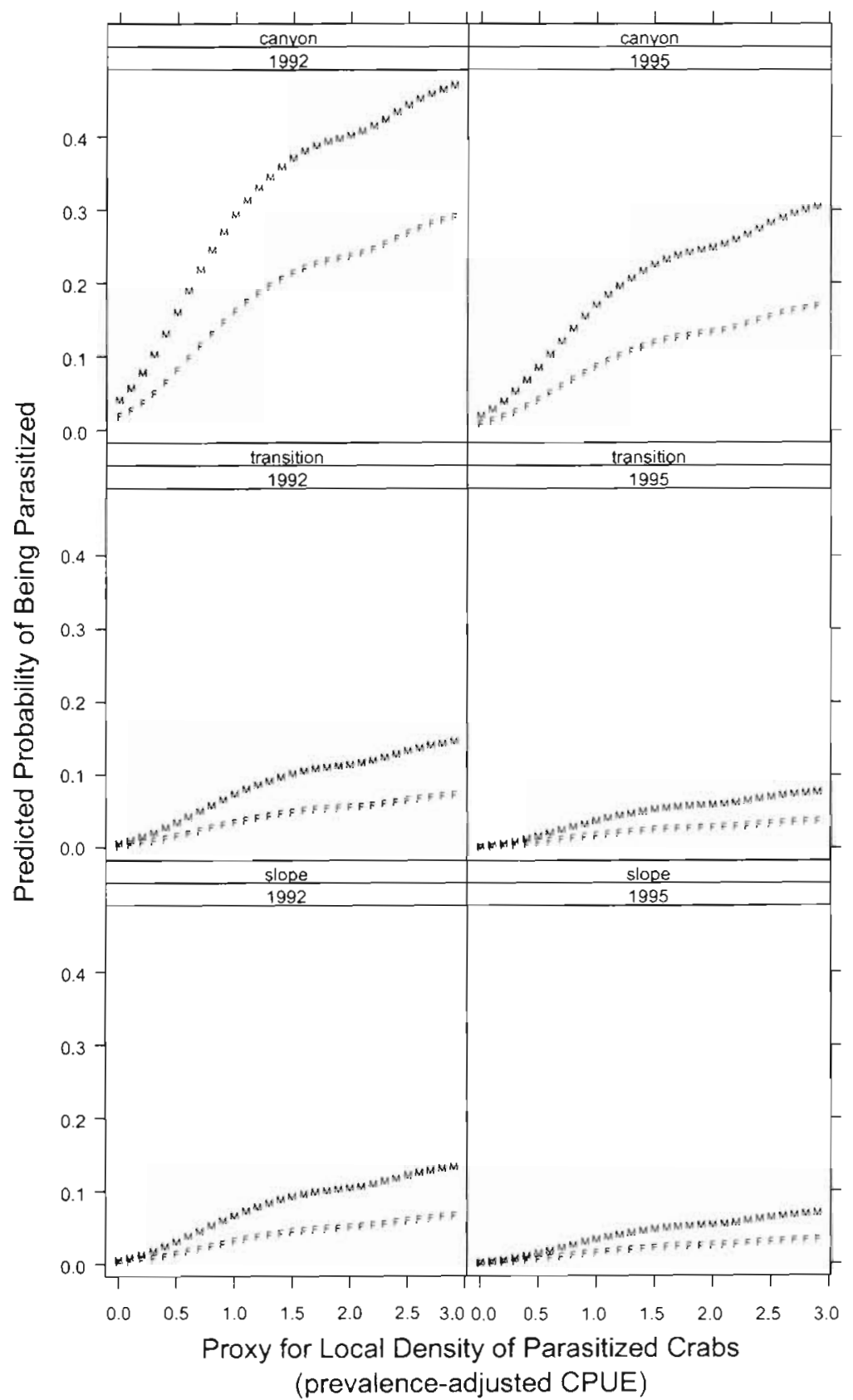

Fig. 4. Relationship between parasite prevalence and parasitized crab density predicted by the combined parasitism model. The predictions were made at the median levels of $s$ (carapace length) and $c d$ (crab density). M: male crabs; F: females. Each panel is a unique combination of year and habitat
Table 6. Analysis of deviance table comparing various models that were used to explain variation in the 1995 hyperparasitism data

\begin{tabular}{|lcccccccc|}
\hline $\begin{array}{l}\text { Model for } \\
\text { 1995 data }\end{array}$ & ID & df & Deviance & $\begin{array}{c}\text { Residual } \\
\text { df }\end{array}$ & $\begin{array}{c}\text { Residual } \\
\text { deviance }\end{array}$ & Test & $\mathrm{p}$ \\
\hline Intercept (null) & 1 & 1 & & 141 & 138.15 & & \\
1992 model & 2 & 3 & 0.00 & 139 & 138.57 & 2 vs 1 & \\
1995 model & 3 & 3 & 2.14 & 139 & 136.01 & 3 vs 1 & 0.343 \\
\hline
\end{tabular}

likely that these differences would be related to differences in grooming behavior rather than to differences in grooming limb morphology. There have been at least 2 comparative studies of grooming limb morphology in anomuran crabs; Pohle (1989) studied lithodids, and Fleischer et al. (1992) 
Table 7 Estimated odds ratios $\hat{\Psi}_{1992+1995}$ from the combined parasitism model. The $95 \%$ confidence limits for $\Psi_{1992+1995}$ are used to test $H_{0}: \Psi_{1992+1995}=1.00(\alpha=0.05)$

\begin{tabular}{|c|c|c|c|c|}
\hline Effect & Versus & $\hat{\Psi}_{1992+1995}$ & $\begin{array}{c}95 \% \text { CI for } \\
\Psi_{1992+1995}\end{array}$ & $\begin{array}{l}\text { Test } H_{0} \text { : } \\
\begin{array}{l}\Psi_{1992+1995} \\
=1.00\end{array}\end{array}$ \\
\hline Male & Female & 2.18 & $(1.76,2.69)$ & Reject \\
\hline Transition & Slope & 1.11 & $(0.83,1.47)$ & Fail to reject \\
\hline Canyon & Slope & 5.70 & $(3.96,8.20)$ & Reject \\
\hline 1995 & 1992 & 0.49 & $(0.37,0.65)$ & Reject \\
\hline
\end{tabular}

studied porcellanids. Both of these studies focused on species-specific differences in pereiopod morphology, but it is reasonable to assume that the authors would have noticed and reported on morphological differences between sexes within a species. Since such reports were rot made, it seems likely that there are not sex-specific differences in grooming limb morphology. In contrast, Fleischer et al. (1992) noted that while many porcellanid species have similar grooming limb morphologies, species-specific differences in susceptibility to parasitism do exist. These differences in susceptibility are behaviorally motivated; after contact with rhizocephalan larvae, some porcellanids initiate gill cleaning more quickly than others. Again, these behavioral differences were not studied in a sex-specific context, but, since female anomurans must clean both their gills and their egg masses (Pohle 1989) while males must only clean their gills, it is possible that behavioral differences in grooming technique and efficiency do exist. Such differences could explain why Briarosaccus callosus is less prevalent on female Paralomis spinosissima.

In a review of rhizocephalan biology, Høeg (1995) noted that these parasites can change the size and shape of their host's pleopods or even cause these appendages to disappear entirely. Sex-specific pleopod loss could cause Briarosaccus callosus to appear to be less prevalent on females than on males. In the 1992 and 1995 data, parasitized females were identified by the presence of pleopods; males were identified by the absence of pleopods. If parasitized, female Paralomis spinosissima lose their pleopods, some of these crabs would have been miscategorized as males. Such miscategorization would have caused the observed prevalence of $B$. callosus on female hosts to be negatively biased. Nielsen (1970) and Attrill (1989) observed that, on pagurid and galatheid hosts respectively, parasitized females often have smaller pleopods than unparasitized females, but neither author observed complete loss of these appendages. Nielsen noted that a reduction of female pleopod size does not indicate masculinization; rather, the observation should be interpreted as a retention of juvenile characters. I am not aware of a comparative study on pleopod size and morphology in parasitized lithodids, but, since variation in host response to parasitism by $B$. callosus is well recognized (Hawkes et al. 1986b), such a study might explain why this rhizocephalan appears to be less prevalent on some female lithodids (including $P$. spinosissima). Perhaps parasitized females from some lithodid species never develop pleopods or maybe these females lose their pleopods entirely.

It is widely recognized that habitat differences contribute to variation in the prevalence of Briarosaccus callosus infection, so the significance of this effect in the combined parasitism model is not surprising. In general, B. callosus is most prevalent inside fjords, bays, and other enclosed bodies of water (Hoggarth 1990). This observation has been made for Lithodes murrayi from the Crozet Islands (Arnaud \& Do-Chi 1977), Lithodes aequispina from British Columbia (Sloan 1984), and Paralithodes platypus from Alaska (Hawkes et al. 1985c, 1986a, b, Sparks \& Morado 1986). Sloan (1984) attributed high prevalence rates in enclosed waters to oceanographic isolation and postulated that enclosed waters help to confine both the host's and the parasite's larvae, thereby creating selfinfecting host populations. Hawkes et al. (1986a, b) attributed site-specific variability in prevalence rates to differences in bottom sediments and proposed that areas with silty bottoms are so turbid that the crabs cannot clean their gills efficiently enough to prevent parasitism.

Preliminarily, it appears that the explanation for habitat specificity in parasite prevalence proposed by Hawkes et al. (1986a, b) is appropriate for the Paralomis spinosissima-Briarosaccus callosus-liriopsinine system around South Georgia. Watters et al. (1995) used a remotely operatec vehicle to survey the benthos around South Georgia, and their video data suggest that the floors of South Georgia's submarine canyons are covered with a loose layer of sediment. Concomitantly, bathymetric charts of South Georgia's coastline do not indicate that there are high sills at the offshore ends of these canyons, and it is probably reasonable to assume that there is water exchange across the canyon-slope transitions (e.g. tides). Thus, the physical conditions at South Georgia would tend to inhibit gill cleaning and reduce larval retention. The latter factor argues against the mechanism for habitat specificity in B. callosus prevalence proposed by Sloan (1984), and the former factor supports the mechanism proposed by Hawkes et al. (1986a, b).

The significance of the [habitat $\cdot$ sex] interaction in the 1992 parasitism model (Table 3) was probably a sampling artifact. The 1992 model was constructed from data that were collected from a single canyon- 
transition-slope system. When a model was fitted to data that were collected from many canyon-transitionslope systems (the 1995 data), the interaction between habitat and sex was not significant (Table 3 ). The different levels of significance in 1992 and 1995 indicate that the interaction between habitat and sex does not hold across the entire study area. Rather, these different levels of significance suggest that there is variability in the relationship between parasite prevalence, habitat, and sex between canyon-transition-slope systems.

The dome-shaped size-prevalence relationship illustrated in Fig. 2 is partially consistent with results from studies on other lithodid-Briarosaccus callosus systems. Many authors have observed that $B$. callosus is less prevalent on large hosts (e.g. Sloan 1984, Hawkes et al. 1985c, 1986a, b, Hoggarth 1990, Otto \& Maclntosh 1996), but evidence for reduced prevalence rates on small hosts is limited (Abelló \& Macpherson 1992). The combined parasitism model's prediction of reduced prevalence on Paralomis spinosissima less than about $60 \mathrm{~mm}$ was influenced by small sample sizes, but 2 of 3 crabs measuring $52 \mathrm{~mm}$ (the smallest size observed for a parasitized crab) were parasitized by $B$. callosus. Most rhizocephalan externae emerge when the host molts (Høeg 1995); crabs are probably infected by B. callosus early in life (Bower \& Sloan 1985); and a single $B$. callosus externa can live on its host for as long as 10 yr (Lützen 1987). These 3 factors make it is reasonable to expect that, as estimated from the presence/absence of externae, size-specific prevalence rates would 'ramp up' after the size of initial parasitization. Such an effect would produce the dome-shaped size-prevalence curve illustrated in Fig. 2. It seems likely that many previous workers did not observe dome-shaped size-prevalence curves because there were too few small crabs in their samples.

There are a number of mechanisms that can cause Briarosaccus callosus to be less prevalent on large hosts. O'Brien \& van Wyk (1985) reviewed sizeprevalence curves from a variety of crab-rhizocephalan systems; parasitic reductions in host growth and parasite-induced host mortalities were identified as likely causes for decreasing size-prevalence curves. Hawkes et al. (1987) used laboratory studies to show that parasitic reduction of host growth occurs in at least one lithodid-B. callosus relationship (the host being Paralithodes platypus) The reduction in host growth is caused both by a decline in molt increment (note that parasitized crabs continued to molt at the same frequency as unparasitized crabs) and an overall reduction in post-molt weight gain. Laboratory studies on the growth of unparasitized and parasitized Paralomis spinosissima have not been conducted, but it would not be surprising if such studies provide results that are consistent with those for $P$ platypus.

Hawkes et al. (1987) discounted the possibility that the decreasing size-prevalence curves observed from a variety of lithodid-Briarosaccus callosus systems are caused by parasite-induced host mortality. This preliminary conclusion was based on the fact that Hawkes et al. did not observe appreciable differences in laboratory survival rates of unparasitized and parasitized Paralithodes platypus. Hawkes et al. did note, however, that their results were based on observations of adult crabs and commented that there should be further investigations on whether there is parasiteinduced mortality of juvenile crabs.

A recent study does, in fact, provide evidence that rhizocephalans can increase mortality rates of juvenile crabs. Alvarez et al. (1995) observed a substantial increase in the intermolt mortality of the xanthid crab Rhithropanopeus harrisii parasitized by the rhizocephalan Loxothylacus panopaei. Most of this parasite-induced mortality occurred during the early stages of the host-parasite relationship, between initial infection and the emergence of the rhizocephalan's externa. Crabs with fully developed externae had a mortality rate similar to that of unparasitized crabs. Alvarez et al. speculated that the crabs which did not survive the emergence of the externa could not withstand the energy demands of the developing parasite and that only the fittest hosts survived the initial stages of infection. Perhaps Briarosaccus callosus, like L. panopaei, increases the mortality of its host during the initial stages of the host-parasite relationship, and, therefore, Hawkes et al. (1987) did not observe differential mortality to parasitized Paralithodes platypus because the observed crabs already had fully developed externae for scars from lost externae). Together, the results of Hawkes et al. (1987) and Alvarez et al. (1995) suggest that parasitic reductions of host growth and parasite-induced host mortality act jointly to make $B$. callosus less prevalent on large hosts.

The combined parasitism model provided the first evidence that the prevalence of Briarosaccus callosus infection is dependent both on local crab density (Fig. 3) and the local density of parasitized crabs (Fig. 4). These results are not consistent with results presented in Table 1 of Sloan (1984). Sloan's data suggest that, for Lithodes aequispina, the prevalence of $B$. callosus was high over a wide range of both crab densities and parasitized crab densities (Table 8). It is not entirely clear why the results in Figs. $3 \& 4$ are not consistent with the results of Sloan (1984). One possible explanation for this discrepancy may be that Sloan's data were summarized on a different spatial scale than the Paralomis spinosissima data. 
Table 8. Relationships between local catch rates of unparasitized and parasitized Lithodes aequispina and prevalences of Briarosaccus callosus. This table is derived from data collected in southeastern Alaska and northern British Columbia and reported in Table 1 of Sloan (1984)

\begin{tabular}{|lcrcr|}
\hline Location & Time & $\begin{array}{c}\text { Crabs } \\
\text { per } \\
\text { trap }\end{array}$ & $\begin{array}{c}\text { Parasitized } \\
\text { crabs } \\
\text { per trap }\end{array}$ & $\begin{array}{c}\text { preva- } \\
\text { lence }\end{array}$ \\
\hline Alice Arm & Oct-Nov 1983 & 23.5 & 9.3 & 39.7 \\
& Feb-Mar 1984 & 15.1 & 6.6 & 43.9 \\
Hastings Arm & Oct-Nov 1983 & 5.9 & 2.3 & 38.4 \\
& Feb-Mar 1984 & 4.9 & 2.1 & 42.4 \\
Observatory & Oct-Nov 1983 & 3.4 & 0.1 & 2.9 \\
Inlet & & & & \\
\hline
\end{tabular}

Sloan (1984) reported catch rates (crab densities) on the basis of large-scale topographical features (i.e. distinct, sill-separated basins in a fjord system) (Table 8), but the Paralomis spinosissima catch rates were modeled on a haul-by-haul basis. Thus, in the $P$. spinosissima data, there were variations in crab density (and parasitized crab density) within large-scale topographical features (e.g. within South Georgia's submarine canyons). The within-habitat effects of crab density and parasitized crab density on the prevalence of Briarosaccus callosus around South Georgia are illustrated as separate panels in Figs. $3 \& 4$. It is not possible to make a comparable, within-location summary of simultaneous variations in CPUE and parasite prevalence from the data in Table 1 of Sloan (1984) (Table 8). On a larger scale, however, the $P$. spinosissima results are similar to Sloan's results. Sloan observed substantial within-year differences in parasite prevalence between distinct fjord basins (compare prevalences in Observatory Inlet to prevalences in Alice or Hastings Arms using the data in Table 8). Similarly, the combined parasitism model predicted that there were large-scale, hajitat-wide differences in parasite prevalence around South Georgia (Table 7, compare different panels in Figs. 3 \& 4).

The asymptotic decline in parasite prevalence associated with increasing density of Paralomis spinosissima (Fig. 3) suggests that, on average, the number of new crabs parasitized by the cyprid larvae released from a single Briarosaccus callosus externa may be independent of crab density. Such a conclusion has important consequences for understanding the ecology of this rhizocephalan; the conclusion implies that some 'limiting factor' is involved in the infection process (the situation is analogous to the role of handling time in Holling's Type II functional response). The nature of this limiting factor is not obvious, but Høeg \& Ritchie (1987) observed that cyprid age limited the successful settlement of Lernaeodiscus porcellanae onto the host crab Petrolisthes cabrilloi. Settlement was most successful during about $4 \mathrm{~d}$ in the middle of the cyprid stage. The authors noted that young cyprids had not developed the physiological and morphological requirements for successful settlement (e.g. cement and cement glands), and, since rhizocephalans have lecithotrophic larvae, old cyprids had depleted the energy reserves required to activate this physiological and morphological machinery. It is possible that cyprid age also affects the settlement success of $B$. callosus.

An alternative, and perhaps more readily acceptable, explanation for the trend in Fig. 3 relates to the behavior of parasitized crabs; a behavioral mechanism can also explain the observation that Briarosaccus callosus is more prevalent when parasitized crab density is high (Fig. 4). Since the crab density estimates were based on the catch rates of legal-sized male Paralomis spinosissima, the trend in Fig. 3 can be interpreted as an indication that parasitized crabs (regardless of sex) do not form dense aggregations with legal-sized males. Likewise, since the parasitized crab density estimates were based on CPUEs that were adjusted by haul-specific prevalence rates, the trend in Fig. 4 may indicate that parasitized crabs do tend to form dense aggregations with other parasitized crabs. Behavioral interpretations of the trends in Figs. $3 \& 4$ would be consistent with Sloan's (1984) observation that parasitized Lithodes aequispina (of both sexes) moved to deep water while unparasitized males were relatively less abundant at depth

It is important to note that the relationship between parasite prevalence and parasitized crab density (Fig. 4) probably does not indicate that a single aggregation of Paralomis spinosissima changes from a state of low prevalence to high prevalence because the aggregation is self-infecting. Such an interpretation would not be consistent with the larval ecology of Briarosaccus callosus. In fact, this rhizocephalan's larval ecology would cause one to expect that prevalence is independent of parasitized crab density. For rhizocephalans, B. callosus has a long larval stage (Hawkes et al. 1985a, Høeg \& Lützen 1995). In the laboratory, Hawkes et al. (1985a) observed that cyprid larvae developed within 20 to $29 \mathrm{~d}$ after hatching as nauplii. The authors noted that the long larval development time would increase the dispersal ability of $B$. callosus. Wide naupliar dispersal would probably cause the abundance of infective cyprids to be independent of parasitized crab density at any given location. It seems likely that the trend in Fig. 4 results from the aggregating behavior of parasitized $P$. spinosissima rather than from parasitization of new individuals in a preformed aggregation. 


\section{Trends in liriopsinine prevalence}

Pohle (1992a, b) and Otto \& MacIntosh (1996) observed Liriopsinae on Briarosaccus callosus but did not identify sources of variation in the prevalence of hyperparasitized crabs. Unfortunately, since neither habitat nor parasitized crab density were consistent, between-year sources of variation in the prevalence of hyperparasitized Paralomis spinosissima (Table 4), this study contributes little new information. It might, however, be reasonable to conclude that, during specific periods of time, habitat is likely to be an important source of variation in liriopsinine prevalence. This conclusion is supported by the significance of the habitat effect in the 1992 hyperparasitism model (Table 4).

Spatial and temporal variation in liriopsinine prevalence may be related to the larval ecology of these hyperparasites. Cryptoniscid life history involves an intermediate host, a copepod, and the infective stage of these isopods is a small larva known as the cryptoniscus (Nielsen \& Strömberg 1973). Perhaps spatially and temporally localized physical or biological processes concentrate either the copepods or the cryptonisci and cause temporal changes in hyperparasite prevalence. Owens (1993) observed a strong seasonal signal in the prevalence of prawns hyperparasitized by a cabiropsinine (recall that the Cabiropsinae and Liriopsinae are both subfamilies in the Cryptoniscidae) and commented that this signal might be attributable to seasonal changes in the abundance of infective cryptonisci. Nielsen \& Strömberg (1965) also noted a seasonal cycle in cabiropsinine prevalence. Bopyrid isopods (recall that these parasites are closely related to the Cryptoniscidae) also have a cryptoniscus stage in their life history. Owens \& Rothlisberg (1995) have shown that a number of environmental factors (e.g. temperature, salinity, and depth) contribute to spatial and seasonal variation in bopyrid cryptoniscus density in the Gulf of Carpentaria. Owens \& Rothlisberg (1995) further noted that the seasonal variation in cryptoniscus density occurs regardless of the fact that there is very little temporal change in the abundance of copepod intermediate hosts. Given the evidence from studies of parasites and hyperparasites with larval ecologies that are similar to those of the Liriopsinae, it would not be surprising to find a seasonal trend in the prevalence of hyperparasitized crabs around South Georgia. This hypothesis cannot, however, be tested with the data sets analyzed in this study.

\section{Parameter stationarity and stability in the host- parasite-hyperparasite system}

The parameters which govern the dynamics of the Paralomis spinosissima-Briarosaccus callosus-liriopsi- nine system may be temporally invariant (stationary). Parameter estimates from one year explained a significant amount of variability in parasite prevalence $3 \mathrm{yr}$ later (Table 5), and the combined parasitism model did not contain significant interactions between year and the other categorical predictors (see 'Results'). Previous authors have not commented on whether the parameters which govern the dynamics of lithodid- $B$. callosus systems are stationary, but the results of this study suggest that, at present, this is a reasonable null hypothesis on which to base future research.

It can also be argued that the between-year comparisons did not provide convincing evidence against stability in the Paralomis spinosissima-Briarosaccus callosus-liriopsinine system. The year effect was significant in the combined parasitism model (Table 3), but this effect may have been a sampling artifact. Recall that the 1992 data were collected from a single canyontransition-slope system, and the 1995 data were collected from many of these systems. The year effect may indicate that there were significant differences in parasite prevalence between canyon-transition-slope systems rather than between years.

Of course, since the data analyzed in this study were not collected over a longer period of time, the lack of evidence against stability in the Paralomis spinosissima-Briarosaccus callosus system should be viewed with some skepticism. Schall \& Marghoob (1995) monitored malaria Plasmodium mexicanum prevalence in the western fence lizard Sceloporus occidentalis over a 13 yr period in northern California. The authors suggested that there was a cyclical trend (with a period of about $10 \mathrm{yr}$ ) in malaria prevalence over the course of the study but noted that this trend was not detected when the data were analyzed after the first 3 yr of the project. There are major differences between lizardmalaria systems and crab-rhizocephalan systems, but the example illustrates that conclusive evidence for or against stability in the $P$. spinosissima- $B$. callosus system will require a longer period of data collection.

It is also difficult to predict whether stability in the Paralomis spinosissima-Briarosaccus callosus-liriopsinine system should be expected on theoretical grounds. Parasites may regulate their host populations to steady densities if parasite-induced host mortality is more pronounced than parasite-induced reduction in host fecundity, especially if the parasites have an aggregated distribution (Hudson \& Dobson 1995). In contrast, host population densities may oscillate if parasite-induced reduction in host fecundity is more pronounced than parasite-induced host mortality; this is particularly true if the parasite distribution is less aggregated (Hudson \& Dobson 1995). The distribution of $B$. callosus is aggregated both among habitats (Figs. 2 to 4 ) and among individual $P$. spinosissima 
(fewer parasitized crabs were observed than unparasitized crabs; see Table 1). However, it is not known whether the parasite's obvious impacts on host fecundity regulate crab densities more than the suggested impact of parasite-induced mortality. It is not even possible to make such a comparison for the B. callosus-liriopsinine relationship because there is no information about whether the hyperparasite causes extra mortality to the parasite.

\section{Summary}

This study can be summarized by putting the results and conclusions into a context that is appropriate for developing a mathematical model of the Paralomis spinosissima-Briarosaccus callosus-liriopsinine system around South Georgia (such a model is presented in Watters \& Deriso unpubl.). A model of the parasitism process in this system should, if possible, include the elements identified in the following list.

(1) Parasitism rates should be sex-specific; this conclusion is supported by the observation that $B$. callosus is less prevalent on female $P$. spinosissima (Table 7 , Figs. 2-4)

(2) Parasitism rates should be habitat-specific; this conclusion is supported by the observation that $B$. callosus is most prevalent in South Georgia's submarine canyons (Table 7, Figs. 2-4).

(3) Parasitism rates should be age/size-specific; this conclusion is supported by the increasing limb of the dome-shaped size-prevalence curve (Fig. 2). This element would, at present, be difficult to incorporate into a host-parasite-hyperparasite model because information on the growth of $P$. spinosissima is very limited.

(4) Mortality rates should be parasitism state-specific so that the possibility of parasite-induced host mortality can be considered; this conclusion is supported by the declining limb of the dome-shaped size-prevalence curve (Fig. 2).

(5) Movement rates should be parasitism state-specific; this conclusion is supported by the decreasing trend in parasite prevalence associated with increasing crab density (Fig. 3) and the increasing trend in parasite prevalence associated with increasing parasitized crab density (Fig. 4).

A model of the hyperparasitism process in the Paralomis spinosissima-Briarosaccus callosus-liriopsinine system could have any of the features described in the preceding list, but, at present, it is not possible to determine whether such features would be realistic. At this point, it would probably be most appropriate to model the dynamics of hyperparasitism in a relatively simple manner (e.g. ignore potential habitat specificity in hyperparasitism rates). Finally, because there is a lack of evidence against parameter stationarity and stability in the $P$. spinosissima-B. Callosus-liriopsinine system, a preliminary host-parasite-hyperparasite model could be developed and fit to data under equilibrium assumptions.

Acknowledgements. This work was supported by the United States Antarctic Marine Living Resources Program, National Oceanic and Atmospheric Administration. Special thanks are due to Robert Otto and Richard MacIntosh who collected and provided most of the 1992 data. Darryl Binney helped collect the 1995 data, and these collections were facilitated by the captain and crew of the F/V 'American Champion'. Four anonymous reviewers made helpful comments on a previous version of this manuscript.

\section{LITERATURE CITED}

Abelló P. Macpherson E (1992) Epibiosis and rhizocephalan infestation patterns in relation to the reproductive biology of Lithodes ferox (Filhol, 1885) (Anomura: Lithodidae). J Crustac Biol 12:561-570

Alvarez F, Hines AH, Reaka-Kudla ML (1995) The effects of parasitism by the barnacle Loxothylacus panopaei (Gissler) (Cirripedia: Rhizocephala) on growth and survival of the host crab Rhithropanopeus harrisii (Gould) (Brachyura: Xanthidae). J Exp Mar Biol Ecol 192:221-232

Arnaud PM, Do-Chi T (1977) Données biologiques et biométriques sur les lithodes Lithodes murrayi (Crustacea: Decapoda: Anomura) des îles Crozet (SW océan Indien). Mar Biol 39:147-159

Attrill MJ (1989) A rhizocephalan (Crustacea; Cirripedia) infestation of the deep-sea galatheid Munida sarsi (Crustacea; Decapoda), the effects on the host and the influence of depth upon the host-parasite relationship. J Zool Lond $217.663-682$

Boschma H (1962) Rhizocephala. Discovery Rep 33:55-94

Bower SM, Sloan NA (1985) Morphology of the externa of Briarosaccus callosus Boschma (Rhizocephala) and the relationship with its host Lithodes aequispina Benedict (Anomura). J Parasitol 71:455-463

British Admiralty (1991) Approaches to South Georgia. Chart 3596

Caullery M (1908) Recherches sur les Liriopsidae, Epicarides cryptonisciens parasites des Rhizocéphales. Mitt Zool Stat Neapel 18:583-643

Chambers JM. Hastie TJ (1993) Statistical models in S. Chapman and Hall, London

Collett D (1991) Modelling binary data. Chapman and Hall, London

Fleischer J, Grell M, Høeg JT, Olesen J (1992) Morphology of grooming limbs in species of Petrolisthes and Pachycheles (Crustacea: Decapoda: Anomura: Porcellanidae): a scanning electron microscopy study. Mar Biol 1.13:425-435

Hastie TJ, Tibshirani RJ (1990) Generalized additıve models. Chapman and Hall, London

Hawkes CR, Meyers TR, Shirley TC (1985a) Larval biology of Briarosaccus callosus Boschma (Cirripedia: Rhizocephala). Proc Biol Soc Wash 98:935-944

Hawkes CR, Meyers TR, Shirley TC (1985b) Parasitism of the blue king crab, Paralithodes platypus, by the rhizocephalan, Briarosaccus callosus. J Invertebr Path 45:252-253

Hawkes CR, Meyers TR, Shirley TC (1985c) The prevalence of the rhizocephalan Briarosaccus callosus Boschma, a parasite in blue king crabs, Paralithodes platypus 
(Brandt), of southeastern Alaska. In: Melteff B (ed) Proceedings of the International King Crab Symposium. Alaska Sea Grant College Program, University of Alaska, Fairbanks, p 353-363

Hawkes CR, Meyers TR, Shirley TC (1986a) Length-weight relationships of blue, Paralithodes platypus, and golden, Lithodes aequispina, king crabs parasitized by the rhizocephalan, Briarosaccus callosus Boschma. Fish Bull US 84: $327-332$

Hawkes CR, Meyers TR, Shirley TC (1987) Growth of Alaskan blue king crabs, Paralithodes platypus (Brandt), parasitized by the rhizocephalan Briarosaccus callosus Boschma. Crustaceana 52:78-84

Hawkes CR, Meyers TR, Shirley TC, Koeneman TM (1986b) Prevalence of the parasitic barnacle Briarosaccus callosus on king crabs of Southeastern Alaska. Trans Am Fish Soc 115:252-257

Høeg JT (1995) The biology and life cycle of the Rhizocephala (Cirripedia). J Mar Biol Assoc UK 75:517-550

Høeg JT, Lützen J (1995) Life cycle and reproduction in the Cirripedia Rhizocephala. Ocean Mar Biol Annu Rev 33: $427-485$

Hoeg JT, Ritchie LE (1987) Correlation between cypris age, settlement rate and anatomical development in Lernaeodiscus porcellanae (Cirripedia: Rhizocephala). J Mar Biol Assoc UK 67:65-75

Hoggarth DD (1990) The effects of parasitism by the rhizocephalan, Briarosaccus callosus Boschma on the lithodid crab, Paralomis granulosa (Jacquinot) in the Falkland lslands. Crustaceana 59:156-170

Hosmer DW, Lemenshow S (1989) Applied logistic regression. John Wiley and Sons, New York

Hudson PJ, Dobson AP (1995) Macroparasites: observed patterns in naturally fluctuating animal populations. In: Grenfell BT, Dobson AP (eds) Ecology of infectious diseases in natural populations. Cambridge University Press, Cambridge, p 144-176

Kuris AM (1974) Trophic interactions: similarity of parasitic castrators to parasitoids. Q Rev Biol 49:129-148

Lützen J (1987) Life history parameters calculated from growth rings in parasitic barnacles of the family Peltogastridae (Crustacea: Cirripedia: Rhizocephala). J Crustac Biol 7:493-506

McCullagh P. Nelder JA (1989) Generalized linear models, 2nd edn. Chapman and Hall, London

Nielsen SO (1970) The effects of the rhizocephalan parasites Peltogaster paguri Rathke and Gemmosaccus sulcatus (Lilljeborg) on five species of paguridan hosts (Crustacea Decapodaj. Sarsia 42:17-32

Nielsen SO, Strömberg JO (1965) A new parasite of Cirolana borealis Lilljeborg belonging to the Cryptoniscinae (Crustacea Epicaridea). Sarsia 18:37-62

Nielsen SO, Strömberg JO (1973) Morphological characters of taxonomical importance in Cryptoniscina (Isopoda Epicaridea): a scanning electron microscopic study of cryptoniscus larvae. Sarsia 52:75-96

O'Brien J, van Wyk P (1985) Effects of crustacean parasitic castrators (epicaridean isopods and rhizocephalan barnacles) on growth of crustacean hosts. Crustac Issues 3 : $191-218$

Editorial responsibility: Otto Kinne (Editor),

Oldendorf/Luhe, Germany
Otto RS, MacIntosh RA (1996) Observations on the biology of the lithodid crab Paralomis spinosissima from the Southern Ocean near South Georgia. In: Proceedings of the International Symposium on Biology, Management, and Economics of Crabs from High Latitude Habitats. Alaska Sea Grant Rep 96-02. University of Alaska, Fairbanks, p 627-647

Owens L (1993) Prevalence of Cabirops orbionei (Epicaridea; Cryptoniscidae) in northern Australia: a biocontrol agent for bopyrids. Aust J Mar Freshwat Res 44:381-387

Owens L, Rothlisberg PC (1995) Epidemiology of cryptonisci (Bopyridae: Isopoda) in the Gulf of Carpentaria, Australia. Mar Ecol Prog Ser 122:159-164

Pohle G (1989) Gill and embryo grooming in lithodid crabs: comparative functional morphology based on Lithodes maja. In: Felgenhauer $\mathrm{BE}$, Watling $\mathrm{L}$, Thistle $\mathrm{AB}$ (eds) Functional morphology of feeding and grooming in Crustacea. AA Balkema, Rotterdam, p 75-94

Pohle G (1992a) First Canadian record of Paralomis bouvieri Hansen, 1908 (Decapoda: Anomura: Lithodidae), infected by the rhizocephalan Briarosaccus callosus (Cirripedia: Peltogastridae) and carrying a hyperparasitic cryptoniscinid isopod (Epicaridea). Can J Zool 70:1625-1629

Pohle G (1992b) First record of the rhizocephalan Briarosaccus callosus (Cirnipedia, Peltogastridae) infecting the Atlantic porcupine stone crab Neolithodes grimaldii (Decapoda, Anomura, Lithodidae). Crustaceana 62:133-136

Ritchie LE, Høeg JT (1981) The life history of Lernaeodiscus porcellanae (Cirripedia: Rhizocephala) and co-evolution with its porcellanid host. J Crustac Biol 1:334-347

Sassaman C (1985) Cabirops montereyensis, a new species of hyperparasitic isopod from Monterey Bay, California (Epicaridea: Cabiropsidae). Proc Biol Soc Wash 98:778-789

Schall JJ, Marghoob AB (1995) Prevalence of a malarial parasite over time and space: Plasmodium mexicanum in its vertebrate host, the western fence lizard Sceloporus occidentalis. J Anim Ecol 64:177-185

Sloan NA (1984) Incidence and effects of parasitism by the rhizocephalan barnacle, Briarosaccus callosus Boschma, in the golden king crab, Lithodes aequispina Benedict, from deep fjords in northern British Columbia, Canada. J Exp Mar Biol Ecol 84:111-131

Sparks AK, Morado JF (1986) Histopathology and host response in lithodid crabs parasitized by Briarosaccus callosus. Dis Aquat Org 2:31-38

Statistical Sciences (1995) S-PLUS guide to statistical and mathematical analysis, Version 3.3. StatSci, MathSoft, Inc, Seattle

Venables WN, Ripley BD (1994) Modern applied statistics with S-Plus. Springer-Verlag, New York

Watters G (1997) Preliminary analyses of data collected during experimental phases of the 1994/95 and 1995/96 Antarctic crab fishing seasons. CCAMLR Sci 4:141-159

Watters G, Bergström B, Gutt J, Pettersson JO, Rosenberg J, Setran A, Valenzuela C (1995) Leg III: Crab and epifaunal surveys of bays, anchorages, and fjords around South Georgia. In: Rosenberg J (ed) AMLR 1994/95 field season report: objectives, accomplishments, and tentative conclusions. United States Department of Commerce, National Oceanic and Atmospheric Administration, Administrative Report LJ-95-13, p 113-130

Submitted: November 17, 1997; Accepted: June 8, 1998

Proofs received from author(s): August 10, 1998 